\title{
Hair loss in sleeve gastrectomy subjects: effects of designed supplements for nutritional deficiencies
}

\author{
Milad Kheirvari ${ }^{1}$, Taha Anbara ${ }^{2}$ \\ 'Microbiology Research Center, Pasteur Institute of Iran, Tehran PC 1316943551, Iran. \\ 2Department of Surgery, Erfan Niayesh Hospital, Tehran PC 1476919491, Iran.
}

Correspondence to: Dr. Taha Anbara, Department of Surgery, Erfan Niayesh Hospital, No. 17, Bahar Intersection, Imam Hossein St., after Kabiri Tameh Blvd., Niayesh Gharb Highway, Tehran PC 1476919491, Iran. E-mail: drtahaanbara@dranbara.com

How to cite this article: Kheirvari M, Anbara T. Hair loss in sleeve gastrectomy subjects: effects of designed supplements for nutritional deficiencies. Mini-invasive Surg 2021;5:40. https://dx.doi.org/10.20517/2574-1225.2021.66

Received: 11 May 2021 First Decision: 15 Jun 2021 Revised: 23 Jun 2021 Accepted: 27 Jul 2021 First online: 3 Aug 2021

Academic Editor: Giulio Belli Copy Editor: Xi-Jun Chen Production Editor: Xi-Jun Chen

\begin{abstract}
Aim: Hair loss is a common complication after bariatric surgery that is related to nutritional deficiencies. The aim of this study was to evaluate the prevalence of micronutrient deficiencies preoperative and postoperative and their relationship with hair loss 12 months after bariatric surgery (BS) in those younger and older than 45 years of age, with or without a prescription for supplements.
\end{abstract}

Methods: In this prospective study, performed between 2018 and 2020 on patients undergoing laparoscopic sleeve gastrectomy (LSG) (not generally BS) in our hospital, the patients were categorized into two main groups of with or without a prescription for supplements. In addition, each main group was divided into age subgroups. Then, complete clinical and biological nutritional assessments were performed in these four subgroups, before and after surgery. Hair loss related to nutritional deficiencies were systematically recorded at 12 months after LSG.

Results: In total, 1224 patients undergoing LSG were enrolled into the study. Nutritional deficits in some variables were even tripled after LSG in both the younger and older groups without a prescription for supplements. In the group with a prescription for supplements, nutritional deficiencies declined postoperatively. The postoperative deficits in the group without a prescription for supplements were frequently in iron (41.83\% for younger group; $44.44 \%$ for older group) and zinc (42.15\% for younger group; $43.79 \%$ for older group). In the group with a prescription for supplements, hair loss was less common than in the group without a prescription for supplements postoperatively.

The Author(s) 2021. Open Access This article is licensed under a Creative Commons Attribution 4.0 International License (https://creativecommons.org/licenses/by/4.0/), which permits unrestricted use, sharing adaptation, distribution and reproduction in any medium or format, for any purpose, even commercially, as long as you give appropriate credit to the original author(s) and the source, provide a link to the Creative Commons license, and indicate if changes were made. 
Conclusion: Preoperative monitoring of the combination of several nutritional deficits could be used to identify patients at risk and prevent the onset of deficiencies and their consequences after BS. Identification and correction of micronutrient deficiencies were essential for treating hair loss.

Keywords: Sleeve gastrectomy, hair loss, older ages

\section{INTRODUCTION}

The prevalence of obesity, over the last three decades, has tripled with an estimated $13 \%$ of adults being obese in $2016^{[1]}$. Obesity is not only a cosmetic concern but also a medical problem that increases the risk of other diseases, such as diabetes, atherosclerotic cardiovascular diseases, high blood pressure, and some kinds of cancers ${ }^{[2-5]}$. According to the World Health Organization (WHO), obesity is defined as "abnormal or excessive fat accumulation that presents a risk to health" ${ }^{[6]}$. Obesity results from a combination of inherited factors, environmental and socioeconomic factors, personal diet, and exercise choices ${ }^{[7]}$.

Bariatric surgery has evolved in the United States and worldwide over the past two decades and is done to help patients lose excess weight and reduce the risk of potentially life-threatening weight-related health problems. Bariatric surgery is a method of treatment that can be used in the case of patients with BMI $\geq$ $35 \mathrm{~kg} / \mathrm{m}^{2}$ and coexisting complications of obesity, such as arterial hypertension, or with BMI $\geq 40 \mathrm{~kg} / \mathrm{m}^{2}$ for normal individuals ${ }^{[8]}$. The two most commonly performed bariatric surgery procedures are Roux-en-Y gastric bypass and sleeve gastrectomy $(\mathrm{SG})^{[9-11]}$. However, these methods are not free from complications, and the most common ones are micronutrient deficiencies because of preoperative malnutrition, decreased food intake due to reduced hunger, and increased satiety and food intolerance or vomiting ${ }^{[2]}$. Some of these deficiencies cause severe clinical impacts, including neurological complications, anemias, bone demineralization, and protein malnutrition ${ }^{[13-15]}$. Moreover, many patients have symptoms suggestive of nutritional deficiencies after BS, but there are few prospective studies to specify their prevalence after surgery ${ }^{[13-16]}$. The frequently reported complications in studies are hair loss, cramps, and paresthesia. These symptoms are more frequent in subjects who are noncompliant to medical visits in the long term after surgery ${ }^{[11]}$.

The main aim of our study was to assess the link between symptoms suggestive of nutritional deficiencies such as hair loss and a large panel of nutritional parameters in subjects who underwent bariatric surgery.

\section{METHODS}

In this prospective study performed on LSG candidates from 2018 to 2020, we included consecutive male and female subjects who underwent LSG at our institution and with complete clinical and biological nutritional assessments performed in Erfan Hospital. The subjects were studied were divided into those younger and older than 45 years of age, with or without a prescription for supplements. Multivitamin supplements were systematically prescribed after surgery, and the reference ranges were recommended by the dietetics and nutritional experts based on age and gender. Hair loss related to nutritional deficiencies was systematically recorded at the 12-month follow-up visit after LSG. Hair loss was defined as either an enhanced amount of hair falling out daily (effluvium) or visible hairlessness (alopecia). Normal hair loss (normal shedding) was referred to the loss of up to 100 hairs per day. Biological parameters (including vitamins $\mathrm{B} 1, \mathrm{~B} 12, \mathrm{C}, \mathrm{A}, \mathrm{E}$, and $\mathrm{D}$ and minerals iron, folic acid, biotin, riboflavin, zinc, and selenium) were assessed using routine techniques ${ }^{[1,17,18]}$. 25-hydroxy vitamin D was assayed with a liquid chromatographytandem mass spectrometry method (Waters Ltd., Elstree, UK). Vitamins A and E were carried out using a high-performance liquid chromatography technique (Agilent Corporation, Santa Clara, CA, USA). Trace 
elements were measured using inductively coupled plasma mass spectrometry (Agilent). Other routine chemistry and hematology analyses were measured on automated platforms (Abbott Diagnostics, Maidenhead, UK; Hobira Medical, Montpellier, France respectively). The daily doses of supplements for patients younger than 45 years of age include: $8 \mathrm{mg}$ of iron for men and post-menopausal women, $18 \mathrm{mg}$ of iron for menstruating women, $30 \mu \mathrm{g}$ of biotin, $11 \mathrm{mg}$ of zinc for men and $8 \mathrm{mg}$ of zing for women, $55 \mu \mathrm{g}$ selenium, $400 \mu \mathrm{g}$ of folic acid, $2.4 \mu \mathrm{g}$ of riboflavin and vitamin B12, $1.2 \mathrm{mg}$ of vitamin B1 for men and $1.1 \mathrm{mg}$ of vitamin B1 for women, $900 \mathrm{mcg}$ of vitamin A for men and $700 \mathrm{mcg}$ of vitamin A for women, $15 \mathrm{mg}$ of vitamin E, $45 \mathrm{mg}$ of vitamin C, and $15 \mathrm{mcg}$ of vitamin D. The only differences in the daily doses of supplements in subjects older than 45 years of age were for iron and zinc, which were prescribed at 18 and $11 \mathrm{mg}$, respectively. More details on the composition of the multivitamin supplement are given in Table 1. Patients initiated supplementation two weeks after surgery and continued for two months. Compliance with supplementation was carefully assessed by the medical follow-up team. This study obtained the ethic code EN2H11935642287TA through the Ethical Board of Erfan Niayesh Hospital.

\section{Surgical technique}

All LSG procedures were carried out by a longitudinal resection from the angle of His to around 3-4 cm orally to the pylorus using a 36-French bougie inserted along the lesser curve. More details on surgical technique have been published previously ${ }^{[19]}$.

\section{Statistical analysis}

All descriptive findings are presented as mean/median and standard deviation for quantitative variables and count and percentage for qualitative variables. After checking the normality of variables using histogram graphs and the Kolmogorov-Smirnov test, the Wilcoxon rank test was used to compare the non-parametric variables and $t$-test to compare other continuous variables before and after LSG. The statistical significance level was defined as $0.05(\alpha=0.05)$. The statistical analyses were performed using IBM SPSS Statistics 25 (SPSS Inc., Chicago, IL).

\section{RESULTS}

For all sleeve gastrectomy candidates in our center, we routinely invited patients to participate in this study. We tried to distribute subjects equally into two groups of males and females and two subgroups of those younger and older than 45 years of age. Of 1224 patients, 612 cases were females (50.0\%) and 612 subjects were males (50.0\%), ranging from 21 to 75 years of age with $612(50.0 \%)$ under 45 years and $612(50.0 \%)$ over 45 years.

\section{Prevalence of preoperative nutritional deficiencies}

Nutritional deficiencies are common issues in morbidly obese subjects. In this prospective study, we recorded every potential deficiency in micronutrients at the first visit before surgery. The most prevalent micronutrients with deficiency in those younger than 45 years were iron $(29.9 \%)$, vitamin D (28.1\%), zinc (27.94\%), vitamin A (24.01\%), and vitamin C (20.9\%). Among those older than 45 years, zinc (27.94\%), iron (25.98\%), vitamin A (25.81\%), vitamin E (25\%), vitamin C (23.69\%), and vitamin D (23.03\%) were the most common deficits before surgery.

\section{Prevalence of postoperative nutritional deficiencies}

Nutritional deficits were observed after BS in both age groups without a prescription for supplements (first group, younger than 45 years of age; second group, older than 45 years of age) [Table 1]. Deficits in the group without a prescription for supplements were frequently in iron (41.83\% for first group; $44.44 \%$ for second group), zinc (42.15\% for first group; $43.79 \%$ for second group), and vitamin A (61.76\% for first group; $58.82 \%$ for second group). In the group with a prescription for supplements, nutritional deficiencies 
Table 1. Prevalence of micronutrient deficiencies in those younger and older than 45 years of age, with or without a prescription for supplements before surgery and at 12 months after LSG

\begin{tabular}{|c|c|c|c|c|c|c|c|c|c|c|c|}
\hline \multirow[b]{2}{*}{ Variables } & \multirow[b]{2}{*}{$\begin{array}{l}\text { Normal levels of } \\
\text { micronutrients in } \\
\text { normal individuals }\end{array}$} & \multicolumn{5}{|c|}{ Younger than 45 years of age } & \multicolumn{5}{|c|}{ Older than 45 years of age } \\
\hline & & $\begin{array}{l}\text { Pre } \\
\text { operative } \\
\text { deficiency }\end{array}$ & $\begin{array}{l}\text { Post operative } \\
\text { deficiency } \\
\text { without } \\
\text { supplement }\end{array}$ & $\begin{array}{l}\text { Supplements } \\
\text { dose - daily } \\
\text { intake }\end{array}$ & $\begin{array}{l}\text { Post operative } \\
\text { deficiency with } \\
\text { supplement }\end{array}$ & P-value ${ }^{1}$ & $\begin{array}{l}\text { Pre } \\
\text { operative } \\
\text { deficiency }\end{array}$ & $\begin{array}{l}\text { Post operative } \\
\text { deficiency } \\
\text { without } \\
\text { supplement }\end{array}$ & $\begin{array}{l}\text { Supplements } \\
\text { dose - daily } \\
\text { intake }\end{array}$ & $\begin{array}{l}\text { Post operative } \\
\text { deficiency with } \\
\text { supplement }\end{array}$ & P-value ${ }^{2}$ \\
\hline$n$ & - & 612 & 306 & - & 306 & - & 612 & 306 & - & 306 & - \\
\hline Iron & $\begin{array}{l}\mathrm{M}: 80-180 \mathrm{mcg} / \mathrm{dL} \\
\mathrm{F}: 60-160 \mathrm{mcg} / \mathrm{dL}\end{array}$ & $183(29.9 \%)$ & $128(41.83 \%)$ & $\begin{array}{l}\text { Men and post- } \\
\text { menopausal } \\
\text { women: } 8 \mathrm{mg} \\
\text { Menstruating } \\
\text { females: } 18 \mathrm{mg}\end{array}$ & $85(27.77 \%)$ & $0.00026^{\star}$ & $\begin{array}{l}159 \\
(25.98 \%)\end{array}$ & $136(44.44 \%)$ & $18 \mathrm{mg}$ & $77(25.16 \%)$ & $<0.00001^{\star}$ \\
\hline Biotin & $133-329 \mathrm{pmol} / \mathrm{L}$ & $60(9.8 \%)$ & $103(33.66 \%)$ & $30 \mu \mathrm{g}$ & $48(15.68 \%)$ & $<0.00001^{*}$ & $66(10.78 \%)$ & $116(37.9 \%)$ & $30 \mu \mathrm{g}$ & $32(10.45 \%)$ & $<0.00001^{*}$ \\
\hline Zinc & $0.66-1.10 \mathrm{mcg} / \mathrm{mL}$ & $171(27.94 \%)$ & $129(42.15 \%)$ & $\begin{array}{l}\mathrm{M}: 11 \mathrm{mg} \\
\mathrm{F}: 8 \mathrm{mg}\end{array}$ & $58(18.95 \%)$ & $<0.00001^{*}$ & $171(27.94 \%)$ & $134(43.79 \%)$ & $11 \mathrm{mg}$ & $55(17.94 \%)$ & $<0.00001^{\star}$ \\
\hline Selenium & $70-150 \mathrm{ng} / \mathrm{mL}$ & $84(13.72 \%)$ & $52(16.99 \%)$ & $55 \mu \mathrm{g}$ & $45(14.7 \%)$ & 0.4413 & $91(14.86 \%)$ & $61(19.93 \%)$ & $55 \mu \mathrm{g}$ & $48(15.68 \%)$ & 0.1706 \\
\hline Folic acid & $2.7-17.0 \mathrm{ng} / \mathrm{mL}$ & $48(7.84 \%)$ & $39(12.74 \%)$ & $400 \mu g$ & $27(8.82 \%)$ & 0.1187 & $55(8.98 \%)$ & $42(13.72 \%)$ & $400 \mu g$ & 25 (8.16\%) & $0.0278^{\star}$ \\
\hline Riboflavin & $4-24 \mu \mathrm{g} / \mathrm{dL}$ & $74(12.09 \%)$ & $41(13.39 \%)$ & $2.4 \mu \mathrm{g}$ & $33(10.78 \%)$ & 0.3221 & 79 (12.90\%) & $46(15.03 \%)$ & $2.4 \mu \mathrm{g}$ & $26(8.49 \%)$ & $0.0120^{*}$ \\
\hline $\begin{array}{l}\text { Vitamin } \\
\text { B12 }\end{array}$ & $200-900 \mathrm{pg} / \mathrm{mL}$ & $72(11.76 \%)$ & $42(13.72 \%)$ & $2.4 \mu \mathrm{g}$ & $24(7.84 \%)$ & $0.018^{*}$ & $96(15.68 \%)$ & $60(19.6 \%)$ & $2.4 \mu \mathrm{g}$ & $39(12.74 \%)$ & $0.0208^{\star}$ \\
\hline Vitamin B1 & $2.5-7.5 \mu \mathrm{g} / \mathrm{dL}$ & $18(2.94 \%)$ & $18(5.88 \%)$ & $\begin{array}{l}\text { M: } 1.2 \mathrm{mg} \\
\mathrm{F}: 1.1 \mathrm{mg}\end{array}$ & $6(1.96 \%)$ & $0.012^{*}$ & $23(3.75 \%)$ & $25(8.16 \%)$ & $\begin{array}{l}\mathrm{M}: 1.2 \mathrm{mg} \\
\mathrm{F}: 1.1 \mathrm{mg}\end{array}$ & $15(4.9 \%)$ & 0.101 \\
\hline Vitamin A & $20-60 \mathrm{mcg} / \mathrm{dL}$ & $147(24.01 \%)$ & $189(61.76 \%)$ & $\begin{array}{l}\text { M: } 900 \mathrm{mcg} \\
\text { F: } 700 \mathrm{mcg}\end{array}$ & $97(31.69 \%)$ & $<0.00001^{*}$ & $158(25.81 \%)$ & 180 (58.82\%) & $\begin{array}{l}\text { M: } 900 \mathrm{mcg} \\
\text { F: } 700 \mathrm{mcg}\end{array}$ & $82(26.79 \%)$ & $<0.00001^{\star}$ \\
\hline Vitamin $\mathrm{E}$ & $5.5-17 \mu \mathrm{g} / \mathrm{mL}$ & $14(2.28 \%)$ & $100(32.67 \%)$ & $15 \mathrm{mg}$ & $59(19.28 \%)$ & $0.00016^{\star}$ & $153(25 \%)$ & 97 (31.69\%) & $15 \mathrm{mg}$ & $43(14.05 \%)$ & $<0.00001^{\star}$ \\
\hline Vitamin C & $0.6-2 \mathrm{mg} / \mathrm{dL}$ & $128(20.91 \%)$ & 97 (31.69\%) & $45 \mathrm{mg}$ & $70(22.87 \%)$ & $0.014^{*}$ & $\begin{array}{l}145 \\
(23.69 \%)\end{array}$ & $94(30.71 \%)$ & $45 \mathrm{mg}$ & $67(21.89 \%)$ & $0.01314^{\star}$ \\
\hline Vitamin D & $20-40 \mathrm{ng} / \mathrm{mL}$ & $172(28.1 \%)$ & 104 (33.98\%) & $15 \mathrm{mcg}$ & $41(13.39 \%)$ & $<0.00001^{\star}$ & $141(23.03 \%)$ & $150(49.01 \%)$ & $20 \mathrm{mcg}$ & $66(21.56 \%)$ & $<0.00001^{\star}$ \\
\hline
\end{tabular}

"P-value significant at $0.05 .{ }^{1} P$-value for statistical analysis of variables between the two subgroups of patients who received supplements and patients who did not receive supplements in the younger than 45 years group. ${ }^{2} P$-value for statistical analysis of variables between the two subgroups of patients who received supplements and patients who did not receive supplements in the older than 45 years group.

were not only better than in the group without a prescription for supplements postoperative, but also better than their evaluations preoperatively [Table 1]. Prevalent nutritional deficiencies in the group with a prescription for supplements were in vitamin A (31.69\% for first group; $26.79 \%$ for second group; $P=$ 0.4354), iron (27.77\% for first group; $25.16 \%$ for second group; $P=0.7489)$, vitamin C (22.87\% for first group; $21.89 \%$ for second group; $P=0.7718)$, and vitamin E (19.28\% for first group; $14.05 \%$ for second group; $P=0.08186)$; the $P$-values for these variables in the groups of those younger and older than 45 years which received supplements mentioned above were not statistically significant. The analysis of the data revealed that the reduction of nutritional 
deficiencies in some variables such as iron $(P=0.00026)$, biotin $(P<0.00001)$, zinc $(P<0.00001)$, vitamin $\mathrm{B} 12(P=0.018)$, vitamin $\mathrm{B} 1(P=0.012)$, vitamin $\mathrm{A}(P<0.00001)$, vitamin $\mathrm{E}(P=0.00016)$, vitamin $\mathrm{C}(P=$ $0.014)$, and vitamin $\mathrm{D}(P<0.00001)$ was significant for patients younger than 45 years of age who received or did not receive supplements. In those older than 45 years, in addition to those variables, folic acid $(P=$ $0.0278)$ and riboflavin $(P=0.012)$ were statistically significant among subjects with or without supplements [Table 1].

\section{Relationship between hair loss and nutritional parameters}

Subjects who complained of hair loss (effluvium or alopecia) were mostly postoperative women without a prescription for supplements (53\% in the younger group; 58\% in the older group), and in the older group without a prescription for supplements hair loss was also more frequent and statistically significant ( $82 \%$ in total) in comparison with the younger group without a prescription for supplements (69\% in total) postoperatively $(P=0.03236)$ [Figure 1 ]. In the group with a prescription for supplements, the rate of hair loss was lower than in the group without a prescription for supplements (40\% overall in the younger group; $36 \%$ overall in the older group) postoperatively [Figure 1]. The prevalence of hair loss regardless of age and gender among subjects with or without a prescription for supplements was significant at $P<0.00001$.

\section{DISCUSSION}

After BS, many subjects complain of symptoms suggestive of nutritional deficiencies, the most frequently reported being hair loss, cramps, and paresthesia. Postoperative symptoms do not result in severe health consequences; they cause a daily discomfort for patients. Hair loss is a common complication after bariatric surgery and is reported in more than half of the subjects in the short term after BS. Hair loss is related to rapid weight reduction; furthermore, zinc, iron, and other micronutrient deficiencies can also be involved ${ }^{[16,17]}$. There are only a few data on the treatment of these symptoms ${ }^{[18]}$. Treatment of hair loss with vitamins $\mathrm{B} 5$ and $\mathrm{B} 6$ is common after $\mathrm{BS}$, whereas there are no data on the association between hair loss after $\mathrm{BS}$ and deficits in these vitamins ${ }^{[11]}$. This is the main reason for our study that aimed to determine the main deficiencies that underlie hair loss and their treatment with supplements after BS.

The frequently reported nutritional deficiencies after BS are iron, vitamin B12, vitamin D, vitamin B1, and zinc deficits ${ }^{[10,11,20-23]}$. In our study, vitamin $A$, iron, and zinc deficits were the most frequently observed after BS. Indeed, we observed a higher prevalence of vitamin A, iron, and zinc deficits in both groups (those younger and older than 45 years of age) without a prescription for supplements compared to both groups with a prescription for supplements.

The analysis of patients with and without a prescription for supplements indicated significant differences for hair loss between the groups with and without hair loss concerning the postoperative use of supplements. The prevalence of hair loss was $69 \%$ and $82 \%$ in the younger and older groups, respectively, 12 months after BS, which is in line with previous reports ${ }^{[24,25]}$. By using the supplements postoperatively, the prevalence of hair loss was only $40 \%$ and $36 \%$ in the younger and older groups, respectively.

Preoperative monitoring of the combination of several nutritional deficits could be used to identify patients at risk and prevent the onset of deficiencies and their consequences after $\mathrm{BS}^{[26]}$. Identification and correction of micronutrient deficiencies was essential for treating hair loss. Our patients stated they benefited from supplements. Indeed, most patients stopped losing hair after being prescribed vitamin and mineral supplements one year after BS. As a consequence, diet counseling and adequate supplementation are required after BS to avoid hair loss. Postoperatively, all patients should receive lifelong supplementation. 


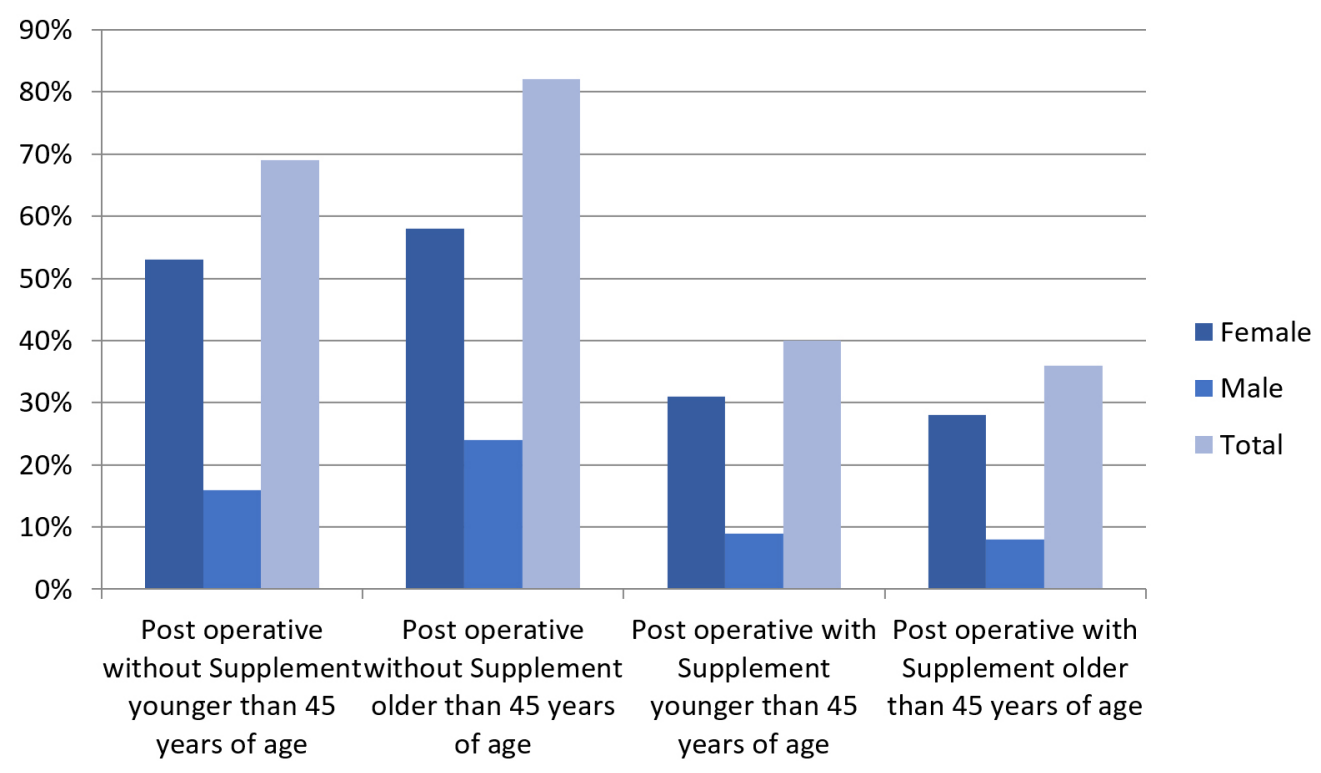

Figure 1. Prevalence of hair loss 12 months after bariatric surgery in those younger and older than 45 years of age, with or without a prescription for supplements. The prevalence of hair loss regardless of age and gender among subjects with or without a prescription for supplements was significant at $P<0.00001$.

In conclusion, hair loss is a frequent postoperative complication after BS in morbidly obese individuals. Based on the results, the variable addition zinc + iron might be one of the predictors of hair loss, although further research is needed to demonstrate the correlation between preoperative status of nutritional deficiency and postoperative remission in bariatric subjects. Therefore, there is global need for monitoring nutrient status in these patients. Most of these deficiencies might be preventable and treatable with highdose supplementation. With increased awareness of the potential nutritional consequences of BS, lifethreatening complications related to nutritional deficits may be avoided.

\section{DECLARATIONS}

\section{Authors' contributions}

Study designe: Anbara T, Kheirvari M

Data cquisition: Anbara T, Kheirvari M

Data analysis: Kheirvari M

Manuscript preparation: Kheirvari M

Supervision: Anbara T

\section{Availability of data and materials}

Readers can reach the data and materials through direct contact to authors' emails.

\section{Financial support and sponsorship}

None.

\section{Conflict of interest}

Both authors declare that there are no conflicts of interest.

\section{Ethical approval and consent to participate}

Informed consent was obtained from all individual participants included in the study. The presented study 
was approved by the Ethical Board of Erfan Niayesh Hospital.

\section{Consent for publication}

Informed consent was obtained from all individual participants included in the study. The presented study was approved by the Ethical Board of Erfan Niayesh Hospital.

\section{Copyright}

(c) The Author(s) 2021.

\section{REFERENCES}

1. Hales CM, Carroll MD, Fryar CD, Ogden CL. Prevalence of obesity among adults and youth: United States, 2015-2016. NCHS Data Brief 2017;288:1-8. PubMed

2. Fontaine KR, Redden DT, Wang C, Westfall AO, Allison DB. Years of life lost due to obesity. JAMA 2003;289:187-93. DOI PubMed

3. Berrington de Gonzalez A, Hartge P, Cerhan JR, et al. Body-mass index and mortality among 1.46 million white adults. $N$ Engl $J$ Med 2010;363:2211-9. DOI PubMed PMC

4. Studies Collaboration. Body-mass index and cause-specific mortality in 900000 adults: collaborative analyses of 57 prospective studies. Lancet 2009;373:1083-96. DOI PubMed PMC

5. Pischon T, Boeing H, Hoffmann K, et al. General and abdominal adiposity and risk of death in Europe. N Engl J Med 2008;359:210520. DOI PubMed

6. Vaamonde JG, Álvarez-món M. Obesidad y sobrepeso. Medicine - Programa de Formación Médica Continuada Acreditado 2020;13:767-76. DOI

7. Chooi YC, Ding C, Magkos F. The epidemiology of obesity. Metabolism 2019;92:6-10. DOI PubMed

8. Fried M, Yumuk V, Oppert JM, et al. International Federation for Surgery of Obesity and Metabolic Disorders-European Chapter (IFSO-EC), European Association for the Study of Obesity (EASO), European Association for the Study of Obesity Obesity Management Task Force (EASO OMTF). Interdisciplinary European guidelines on metabolic and bariatric surgery. Obes Surg 2014;24:42-55. DOI

9. Campos GM, Khoraki J, Browning MG, Pessoa BM, Mazzini GS, Wolfe L. Changes in utilization of bariatric surgery in the United States from 1993 to 2016. Ann Surg 2020;271:201-9. DOI PubMed

10. Dogan K, Homan J, Aarts EO, de Boer H, van Laarhoven CJHM, Berends FJ. Long-term nutritional status in patients following Rouxen-Y gastric bypass surgery. Clin Nutr 2018;37:612-7. DOI PubMed

11. Ledoux S, Calabrese D, Bogard C, et al. Long-term evolution of nutritional deficiencies after gastric bypass: an assessment according to compliance to medical care. Ann Surg 2014;259:1104-10. DOI PubMed

12. Kheirvari M, Dadkhah Nikroo N, Jaafarinejad H, et al. The advantages and disadvantages of sleeve gastrectomy; clinical laboratory to bedside review. Heliyon 2020;6:e03496. DOI PubMed PMC

13. Tabbara M, Carandina S, Bossi M, Polliand C, Genser L, Barrat C. Rare neurological complications after sleeve gastrectomy. Obes Surg 2016;26:2843-8. DOI PubMed

14. Punchai S, Hanipah ZN, Meister KM, Schauer PR, Brethauer SA, Aminian A. Neurologic manifestations of vitamin B deficiency after bariatric surgery. Obes Surg 2017;27:2079-82. DOI PubMed

15. Via MA, Mechanick JI. Nutritional and micronutrient care of bariatric surgery patients: current evidence update. Curr Obes Rep 2017;6:286-96. DOI PubMed

16. Folope V, Coëffier M, Déchelotte P. Carences nutritionnelles liées à la chirurgie de l'obésité. Gastroentérologie Clinique et Biologique 2007;31:369-77. DOI

17. Ruiz-Tovar J, Llavero C, Zubiaga L, Boix E; OBELCHE group. Maintenance of multivitamin supplements after sleeve gastrectomy. Obes Surg 2016;26:2324-30. DOI PubMed

18. Katsogridaki G, Tzovaras G, Sioka E, et al. Hair loss after laparoscopic sleeve gastrectomy. Obes Surg 2018;28:3929-34. DOI PubMed

19. Kheirvari M, Akbarzadeh I, Eshghjoo S, et al. Diagnostic value of erythrocyte sedimentation rate levels as a predictor of staple-line leakage in bariatric surgery. Bariatr Surg Pract Patient Care 2020;15:231-5. DOI

20. Coupaye M, Rivière $\mathrm{P}$, Breuil MC, et al. Comparison of nutritional status during the first year after sleeve gastrectomy and Roux-en-Y gastric bypass. Obes Surg 2014;24:276-83. DOI PubMed

21. Caron M, Hould FS, Lescelleur O, et al. Long-term nutritional impact of sleeve gastrectomy. Surg Obes Relat Dis 2017;13:1664-73. DOI PubMed

22. Al-Mutawa A, Al-Sabah S, Anderson AK, Al-Mutawa M. Evaluation of nutritional status post laparoscopic sleeve gastrectomy-5-year outcomes. Obes Surg 2018;28:1473-83. DOI PubMed

23. Pellitero S, Martínez E, Puig R, et al. Evaluation of vitamin and trace element requirements after sleeve gastrectomy at long term. Obes Surg 2017;27:1674-82. DOI PubMed

24. Ruiz-tovar J, Oller I, Llavero C, et al. Hair loss in females after sleeve gastrectomy: predictive value of serum zinc and iron levels. The 
American Surgeon 2014;80:466-71. PubMed

25. Rojas P, Gosch M, Basfi-fer K, et al. Alopecia in women with severe and morbid obesity who undergo bariatric surgery. Nutr Hosp 2011;26:856-62. DOI PubMed

26. Tang L, Alsulaim HA, Canner JK, Prokopowicz GP, Steele KE. Prevalence and predictors of postoperative thiamine deficiency after vertical sleeve gastrectomy. Surg Obes Relat Dis 2018;14:943-50. DOI PubMed 